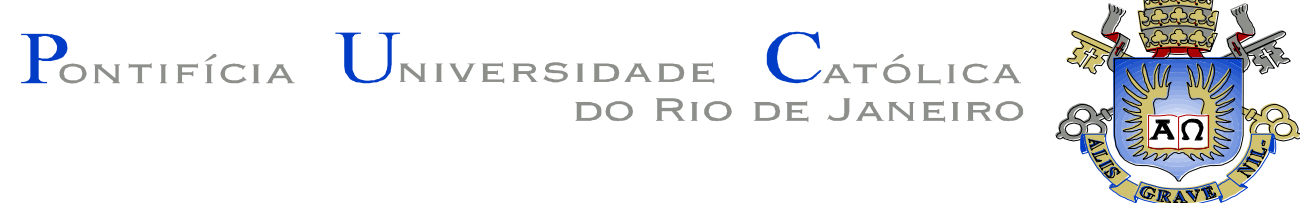

Romildo Henriques Pinas

\title{
ABERTURA AO MISTÉRIO DE DEUS E REVELAÇÃO SALVÍFICA EM W. PANNENBERG Em Jesus Cristo a história humana se eleva ao divino
}

Tese de Doutorado

Tese apresentada ao Programa de PósGraduação em Teologia da PUC-Rio como requisito parcial para obtenção do título de Doutor em Teologia.

Orientador: Prof. Mário de França Miranda

Rio de Janeiro Março de 2012 


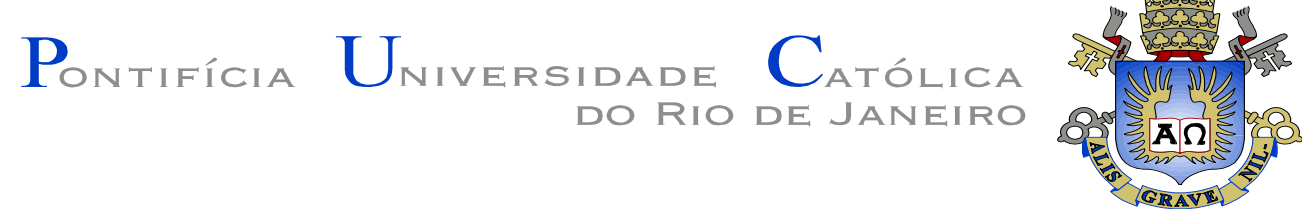

Romildo Henriques Pinas

\begin{abstract}
Abertura ao mistério de Deus e revelação salvífica em $\mathbf{W}$.
Pannenberg. Em Jesus Cristo a história humana se eleva ao divino
\end{abstract}

Tese apresentada como requisito parcial para obtenção do grau de Doutor pelo Programa de Pós-Graduação em Teologia do Departamento de Teologia do Centro de Teologia e Ciências Humanas da PUC-Rio. Aprovada pela Comissão Examinadora abaixo assinada.

\author{
Prof. Mário de França Miranda \\ Orientador \\ Departamento de Teologia - PUC-Rio
}

Prof. Joel Portella Amado

Departamento de Teologia - PUC-Rio

Prof. Antônio José Afonso da Costa

Departamento de Teologia - PUC-Rio

Prof. Cleto Caliman

Pontifícia Universidade Católica de Minas Gerais

Prof. Luis Maurício Telles da Silva

ISTARJ

Prof ${ }^{a}$. Denise Berruezo Portinari

Coordenadora Setorial de Pós-Graduação e Pesquisa do Centro de

Teologia e Ciências Humanas - PUC-Rio

Rio de Janeiro, 14 de março de 2012 
Todos os direitos reservados. É proibida a reprodução total ou parcial do trabalho sem autorização do autor, do orientador e da universidade.

\section{Romildo Henriques Pinas}

Graduou-se em Filosofia Na PUC-Minas (Pontifícia Universidade Católica de Minas Gerais) em 1996. Pósgraduado em Filosofia Contemporânea, também pela PUCMinas em 1998. Bacharelou-se em Teologia pelo Instituto Santo Tomás de Aquino em Belo Horizonte - MG em 2002. Cursou Mestrado em Teologia Sistemática na PUC-Rio em 2007. Atualmente trabalha no SSAS (Sistema Salesiano de Assistência Social) da Inspetoria São João Bosco (ISJB), atuando na animação de uma obra social na cidade de Niterói, Rio de Janeiro.

Ficha Catalográfica

Pinas, Romildo Henriques

Abertura ao mistério de Deus e revelação salvífica em W. Pannenberg. Em Jesus Cristo a história humana se eleva ao divino/ Romildo Henriques Pinas; orientador: Mario de França Miranda. Rio de Janeiro: PUC-Rio, Departamento de Teologia $-2012$.

v., 266 f. ; $30 \mathrm{~cm}$

Tese (doutorado) - Pontifícia Universidade Católica do Rio de Janeiro, Departamento de Teologia.

Inclui bibliografia

1. Teologia - Teses. 2. Antropologia 3. Revelação 4. História. 5. Pannenberg, Wolfhart. I. Miranda, Mario de França. II. Pontifícia Universidade Católica do Rio de Janeiro. Departamento de Teologia. III. Título. 


\section{Agradecimentos}

No silêncio misterioso do princípio originário da vida uma pergunta se faz ecoar no mais profundo do meu ser: por que eu fui chamado à vida? Nas inquietações da existência, como apelos do espírito, nos atiramos em busca das mais diversas respostas. O desejo de respostas vai como que sombreando a margem do nosso peregrinar pela vida. Tal desejo não nos abandona um instante sequer, ele é como um destino fatal que sempre nos atormenta na busca de mais e mais. $O$ eco ensurdecedor da voz deste desejo, que grita numa fome infinita de conhecimento do Absoluto, é talvez, o que tenha impulsionado Agostinho a afirmar "tarde Senhor, te conheci”. Aqui antes de tudo, agradeço a Deus por ter colocado em mim o desejo de conhecê-lo, mais que conhecê-lo, amá-lo. Agradeço, sobretudo, pelo seu amor infinito manifestado a toda humanidade em Jesus Cristo.

Agradeço à minha família, que tanto me assistiu durante esse trabalho, sabendo compreender os momentos que tive que me ausentar fisicamente. Todos os meus irmãos nunca me deixaram de apoiar nesse empreendimento. Lembro aqui minha mãe (in memoriam), mulher simples e trabalhadora, fez da vida um sinal do amor de Deus no mundo. Meu pai (in memoriam), homem honrado e trabalhador que soube educar os filhos para o direito e para a fraternidade.

De forma especial, demonstro minha gratidão ao Dr. Mario de França Miranda, docente da Pontifícia Universidade Católica do Rio de Janeiro, orientador disponível, sério e seguro; homem que desde a primeira aula aprendi a admirar e valorizar em suas incomensuráveis qualidades, sobretudo, pela bondade e compreensão para com seus alunos - pessoa profundamente humana. Mesmo sendo 
grande, renomado no mundo da teologia, sabe caminhar com os pequenos e auxiliálos nas dificuldades. Age com misericórdia, sem perder o extremo rigor das exigências acadêmicas. Na sua forma de vida a teologia se manifesta na cotidiana prática do amor fraterno.

Aos professores e funcionários do Departamento de Teologia da PUC-RJ, não me constranjo em citar o pe. Alfonso Garcia, homem admirável, integrado e afetuoso para com seus alunos, intelectual respeitado e exigente. Ao Sérgio e Jussara que sempre atendem na secretaria com profissionalismo e cordialidade.

Não poderia deixar de manifestar o meu sincero agradecimento aos meus colegas de grupo da Pós-Graduação em teologia, pois durante os debates muito contribuíram para o melhor desenvolvimento da pesquisa.

Agradeço ao CNPq (Conselho Nacional de Desenvolvimento Científico e Tecnológico) e à PUC-Rio que ajudaram nessa pesquisa.

Por fim, agradeço à Inspetoria São João Bosco (ISJB) na pessoa do pe. Nilson Faria dos Santos, atual inspetor, onde passei a maior parte de minha vida; nesta minha nova casa, desde adolescente, adquiri gosto pelos livros e pela cultura. Agradeço com todo carinho a minha comunidade, ela muito me ajudou na realização desse trabalho com sugestões e diálogos. Menciono de forma especial pe. Josué pela ajuda na revisão do português.

A todos minha eterna gratidão. 


\section{Resumo}

Henriques, Romildo Pinas; Miranda, Mário de França. Abertura ao mistério de Deus e revelação salvífica em W. Pannenberg. Em Jesus Cristo a história humana se eleva ao divino. Rio de Janeiro, 2012. 266p. Tese de Doutorado - Departamento de Teologia, Pontifícia Universidade Católica do Rio de Janeiro.

O presente estudo procura refletir a problemática da relação ser humano e Deus no pensamento de Wolfhart Pannenberg. Para a elaboração do trabalho foram consideradas duas temáticas de grande relevância no autor mencionado: a antropologia e a história. A primeira parte se encarrega em apresentar os fundamentos antropológicos da dimensão religiosa. Para isso foi importante compreender o conceito de pessoa, de sujeito e de liberdade em nosso autor. Em Pannenberg, o tema da abertura caracteriza uma antropologia que não se fecha diante do puro imanente, mas se coloca frente ao infinito mistério de Deus. O ser humano é aquele que transcende a sua finitude e se abre ao infinito. A noção de imagem e semelhança de Deus oferece bases para uma leitura teológica da antropologia. A segunda parte trabalha o tema da revelação como história no contexto judaico - cristão. Conforme o teólogo alemão a revelação se dá de forma indireta através dos acontecimentos históricos. Nesse sentido a primeira parte se harmoniza com a segunda, pois somente se pode falar de história se consideramos o ser humano como seu protagonista. É na história humana que Deus se revela como criador, libertador e salvador da humanidade. O ápice da revelação se dá em Jesus Cristo, pois nele ela chega ao seu ponto final. Jesus já é de forma proléptica o que acontecerá com todo ser humano. A sua ressurreição antecipa a esperança futura reservada a cada pessoa. Em conformidade com o que foi afirmado, a escatologia se faz muito importante para o teólogo luterano. É nela que acontecerá o desfecho final da história humana, chamado por ele de fim da história. Jesus Cristo é o centro unificador desse futuro, em que haverá uma perfeita harmonia entre passado, presente e futuro no presente eterno de Deus. A realização final da pessoa será a 
eterna participação do amor divino, da trindade. Amor já manifestado pelo Pai desde o início da criação.

\section{Palavras-chave}

Revelação; antropologia; história; Deus; Wolfhart Pannenberg 


\section{Abstract}

Henriques, Romildo Pinas; Miranda, Mário de França (Advisor). Opening to the mystery of God and saving revelation in W. Pannenberg. In Jesus Christ the human history rises to the divine. Rio de Janeiro, 2012. 266p. Thesis Doctorate - Departamento de Teologia, Pontifícia Universidade Católica do Rio de Janeiro.

The present study aims at reflecting the problem of the relationship between human beings and God in Wolfhart Pannenberg's thought. Two issues of great importance in Pannenberg's work were taken into consideration: anthropology and history. The first presents the anthropological foundations of the religious dimension. For that matter, it is important to understand the concept of person, subject and freedom in Pannenberg. For him the opening theme features an anthropology that does not close itself before the immanent pure, but it is placed against the infinite mystery of God. The human being transcends its finitude and opens himself to infinity. The notion of image and likeness of God provides a foundation for a theological reading of anthropology. The second part works with the theme of revelation as history in the Jewish-Christian context. According to the German theologian, the revelation is given indirectly through historic events. In this sense the first part agrees with the second because one can only talk about history if we consider man as the performer. It is in human history that God reveals himself as the creator, liberator and savior of humanity. The apex of revelation is in Jesus Christ, for there it reaches its end. Jesus is already in a prolepsis of what will happen to every human being. His resurrection anticipates the future hope reserved for each person. In accordance with what was said, eschatology becomes very important for the Lutheran theologian. That is where the final outcome of human history will happen - what he calls the end of history. Jesus Christ is the unifying center of the future, when there will be a perfect harmony of past, present, and future in the eternal present of God. The ultimate realization of the person will be eternal 
participation in the love of God, the Trinity. Love that the Father has already expressed since the beginning of creation.

\section{Keywords}

Revelation; anthropology; history; God; and Wolfhart Pannenberg. 


\section{Sumário}

$1 \quad$ Introdução geral $\quad 15$

2 W. Pannenberg, a modernidade e o ser humano como centro 22

- antropocentrismo

2.1 Wolfhart Pannenberg e sua produção acadêmica 23

2.2 Alguns pressupostos para compreender o ser humano: as 31

2.2.1 O Corpo como dimensão essencial da pessoa humana 32

2.2.2 O espírito humano na antropologia teológica de Pannenberg 36

2.2.2.1 A abordagem de espírito na antropologia filosófica 37

2.2.2.2 O espírito como dimensão da pessoa humana na linguagem 40 bíblico-cristã

2.3 O ser humano diante da razão moderna - a secularização 46

2.3.1 A Relação entre indivíduo e sociedade - fechamento e 52 abertura

2.3.2 Personalismo dialógico o "eu" e o "tu" na formação da vida em 58 sociedade

2.3.3 O ser humano como abertura 60

3 A existência humana como transcendência 66

3.1 A cultura como realidade que se transcende 67

3.2 O indivíduo como liberdade e consciência 70

3.3 A pessoa humana como ser transcendente 76

3.3.1 A transcendência como poder de superação do ser humano 79

3.3.2 Transcendência humana e história 83

3.3.3 Transcendência e história no cristianismo 86

$4 \quad$ O ser humano como abertura para Deus - a natureza religiosa 91 do ser humano em Pannenberg

4.1 O ser religioso na antropologia de W. Pannenberg 92

4.1.1 A validade da dimensão religiosa do ser humano 92

4.1.2 Confiança e abertura - características do ser religioso da 97 pessoa humana

4.1.3 A pessoa como identidade religiosa 101

4.2 A abordagem bíblica e outras abordagens do tema da imagem 104 e semelhança de Deus no decorrer da história cristã

4.3 A imagem e semelhança de Deus e o mundo SEGUNDA PARTE

5 Deus se revela na história da salvação - uma leitura teológica da história

5.1 O processo histórico

5.1.1 A história da criação, sustentação e governo do mundo 122

$\begin{array}{ll}\text { 5.1.2 Pecado e infidelidade } & 127\end{array}$ 
5.1.2.1 A origem do pecado

5.1.2.2 Os temas do mal e do pecado na Bíblia e na história humana 130

5.1.2.3 A problemática do pecado e da culpa

5.2 A questão histórica como problema teológico

5.2.1 Eleição e historicidade em Israel

5.2.2 Deus presente na história de Israel - a revelação como história

5.3 A compreensão de revelação para a teologia de Pannenberg

5.4 A auto-revelação indireta de Deus e os questionamentos de Pannenberg à noção de revelação da teologia da palavra

5.5 Israel espera a libertação - Deus salva

5.5.1 Deus liberta e salva a pessoa humana na história

5.5.2 A revelação como futuro histórico - a realização do reino de Deus

6 Jesus Cristo como sentido último da história humana - a história particular se eleva à história universal

6.1 O Verbo se encarna e o ser humano se reconcilia com Deus na pessoa de Jesus Cristo

6.2 A compreensão teológica da pessoa de Jesus enquanto encarnação na história

6.3 Jesus Cristo como revelação de Deus no ser humano

6.3.1 Jesus Cristo como protótipo de pessoa na antropologia teológica cristã

6.3.2 Na história de Jesus converge a de toda humanidade - a salvação para todos

6.4 A pessoa de Jesus e o reino de Deus

6.5 Jesus como futuro da humanidade - um novo sentido para a historicidade humana

6.5.1 Jesus como resposta para o futuro da humanidade

6.5.2 Libertados plenamente no Deus de Jesus Cristo

6.5.2.1 A noção bíblico-cristã do tema liberdade

202

205

6.5.3 Jesus o Cristo salva e reconcilia o gênero humano

7 A plenitude do destino humano - transcendência da história e na história - o já e o "ainda não" no tempo escatológico 
7.1 A escatologia na história

7.1.1 O "já" e o "ainda não" no tempo escatológico

7.1.2 Passado, presente e futuro - a totalidade da história

7.2 Em Jesus a história humana se eleva ao divino

7.2.1 A revelação como história

225

7.2.2 Cristo como centro unificador da história: a ressurreição como plenitude do destino humano

7.3 A noção de ressurreição dos mortos

230

7.3.1 A ressurreição de Jesus

234

7.3.2 O amor de Deus como plenitude do destino humano

8 Conclusão geral

242

$9 \quad$ Referências bibliográficas 


\section{Abreviações}

\begin{tabular}{ll} 
ATP & Anthropologie in theologischer Perspektive \\
BG & Bewusstsein und Geist \\
BSTh1 & Beiträge zur Systematischen Theologie Band 1 \\
BSTh2 & Beiträge zur Systematischen Theologie Band 2 \\
ChSW & Christentum in einer sakularisierten Welt \\
CDRJ & Consideraciones dogmáticas acerca de la \\
& Resurreccion de Jesus \\
1Cor & 1 Epístola aos Coríntios \\
2 Cor & $2^{a}$ Epístola aos Coríntios \\
Dn & Daniel \\
Dt & Deuteronômio \\
Ef & Epístola aos Efésios \\
Ex & Exodo \\
FI & Epístola aos Filipenses \\
Gl & Epístola aos Gálatas \\
GC & Grundzüge der Christologie \\
Gn & Gênesis \\
GSTh1 & Grundfragen systematischer Theologie Band 1 \\
GSTh2 & Grundfragen systematischer Theologie Band 2 \\
Hb & Epístola aos Hebreus \\
Jl & Joel \\
Jo & Evangelho de João \\
1 Jo & 1 É Epístola de João \\
Jó & Jó \\
Jr & Jeremias \\
KuD & Kerygma und Dogma \\
Lc & Evangelho de Lucas \\
Mc & Evangelho de Marcos \\
MIG & Metaphysics \& the Idea of God \\
Mq & Miquéias \\
Mt & Evangelho de Mateus \\
Nm & Números \\
OG & Offenbarung als Geschichte \\
REB & Revista Eclesiástica Brasileira \\
Rm & Epístola aos Romanos \\
SI & Salmos \\
ST1 & Systematische Theologie Band 1 \\
ST2 & Systematische Theologie Band 2 \\
-- & \\
& \\
\hline &
\end{tabular}


ST3

TF

ThLZ

TRD

1Ts

$\mathrm{Tt}$

WM

WT

Zc

ZKTh

ZThK
Systematische Theologie Band 3

Teologia e Filosofia

Theologische Literaturzeitung

Teologia y Reino de Dios

$1^{a}$ Epístola aos Tessalonicenses

Epístola a Tito

Was ist der Mench?

Wissenschaftstheorie und Theologie

Zacarias

Zeitschrift für Katholische Theologie

Zeitschrift für Theologie und Kirche 